\title{
Valsartan Ingestions Among Adults Reported to Texas Poison Control Centers, 2000 to 2005
}

\author{
Mathias B. Forrester, BS ${ }^{a}$
}

aTexas Department of State Health Services, Austin, Texas

\begin{abstract}
Introduction: Little data exist on potentially adverse valsartan ingestions reported to poison control centers.

Methods: Using adult ingestions of valsartan reported to Texas poison control centers during 2000-2005, I determined the proportion of cases involving serious outcomes for selected variables and evaluated for statistical significance by calculating the rate ratio (RR) and 95\% confidence interval (CI).

Results: Thirteen (7\%) of 185 total cases involved serious outcomes. Serious outcomes were significantly more likely to occur with a maximum dose $>320 \mathrm{mg}$ (RR 9.06, CI 1.30-100.14) or $>4$ tablets (RR 9.00, CI 2.07-39.11) or where the circumstances of the exposures involved self-harm or malicious intent (RR 17.28, CI 4.98-67.13).

Conclusions: The severity of the medical outcome associated with adult valsartan ingestions depended on the dose and the circumstances of the ingestion. Such information is useful for creating triage guidelines for the management of adult valsartan ingestions.
\end{abstract}

\section{INTRODUCTION}

Valsartan, (Diovan ${ }^{\circledR}$, Novartis), chemical name $N$-(1-oxopentyl)$N$-[[2'-(1H-tetrazol-5-yl)[1,1'-biphenyl]-4-yl]methyl]-L-valine, is an angiotensin II receptor antagonist or blocker. It acts by selectively preventing the binding of angiotensin II, a vasoconstrictor and growth-stimulating hormone, to the $\mathrm{AT}_{1}$ receptor subtype of the angiotensin II receptor, thus blocking the vasoconstrictive and aldosterone-secreting effects of angiotensin II [1-4]. Valsartan is indicated for the treatment of hypertension and heart failure and for the reduction of cardiovascular mortality after myocardial infarction [1-5]. The drug's effects are dose-dependent [3].

In therapeutic doses, valsartan has a bioavailability of $19-25 \%$ [1-5]. Its elimination half-life is 5-9 hours, and it is eliminated mostly unchanged in feces (80-85\%) and urine (7-13\%) [1-5].
The most likely adverse clinical effects associated with valsartan overdose are hypotension and tachycardia [5]. Other adverse clinical effects reported with valsartan use include dizziness, diarrhea, arthralgia, fatigue, drowsiness, nausea, abdominal pain, blurred vision, syncope, headache, cough, rhinitis, sinusitis, and edema [1,3-7]. The recommended treatment of adverse valsartan ingestions includes decontamination or increased elimination via such methods as lavage or activated charcoal and supportive care [4-5]. IV fluids may be used to manage hypotension [4]. Valsartan is not removed by hemodialysis [5].

The US Food and Drug Administration approved valsartan for use in January 1997. The drug is available in tablets with formulations of 40, 80, 160, and $320 \mathrm{mg}$ [5]. The recommended dose is $80-320 \mathrm{mg}$ daily $[1,2,5]$.

Potentially adverse exposures to angiotensin receptor blockers, including valsartan, are spontaneously and voluntarily reported

Keywords: valsartan, poison centers, adverse exposures

Notes: Funding for this research was provided by a contract with the Commission on State Emergency Communications in Texas.

Acknowledgements: I would like to thank the staff of the six poison centers (Central Texas Poison Center, North Texas Poison Center, Texas Panhandle Poison Center, South Texas Poison Center, Southeast Texas Poison Center, West Texas Regional Poison Center) of the Texas Poison Center Network who collected the data.

Corresponding Author: Mathias B. Forrester, BS, Epidemiology and Disease Surveillance Unit, Texas Department of State Health Services, 1100 W 49th Street, Austin, TX 78756. Email: mathias.forrester@dshs.state.tx.us 
to poison control centers in the US. During 2003-2004, these poison control centers received calls involving over 10,000 angiotensin receptor blocker exposures, of which more than 6,600 involved adult patients. Several of the valsartan exposures resulted in death $[8,9]$.

The American Association of Poison Control Centers (AAPCC) has drafted management guidelines for the cardiovascular drug groups of calcium channel blockers and beta blockers [10,11]. At the time of this analysis, similar management guidelines for angiotensin II receptor blockers were not available. Moreover, I derived much of the information on potentially adverse valsartan exposures from clinical studies. The intent of this investigation was to describe the pattern of adult valsartan ingestions reported to Texas poison control centers and to suggest potential triage guidelines for the management of such ingestions.

\section{METHODS}

This was a retrospective study using previously collected data by the six poison control centers that cover all of Texas; these centers are collectively known as the Texas Poison Center Network (TPCN). All of these poison control centers use the same Toxicall software and Toxic Exposure Surveillance system (TESS) to collect data on all calls.

Cases were all ingestions of valsartan by patients $\geq 20$ years of age who reported to the TPCN during 2000-2005. In these cases, valsartan was the only ingested drug. The maximum dose involved in an ingestion is not recorded in the TESS database in a consistent manner, so I attempted to determine the maximum dose in milligrams by reviewing the following data fields: dose, concentration, quantity, verbatim name, and notes. The maximum dose in milligrams could not be determined for many of the cases, and so I also attempted to determine the maximum number of tablets ingested by using the same data fields.

In addition to the maximum dose (in milligrams and tablets), the distribution of cases was determined for the following variables: patient gender, exposure site, circumstances of the exposure, management site, severity of medical outcome, and listed adverse clinical effects and treatments. The subgroups for these variables were based on those included in the TESS database.

The circumstances of the exposure were grouped into those involving intentional self-harm or malicious intent (such as suspected attempted suicide) and all other circumstances (such as accidental, therapeutic error). The poison control center staff, managing the exposure, assigned the severity of medical outcome based on the adverse clinical effects observed or anticipated. The TESS database subgroups, for severity of medical outcome, were sorted into two categories:

Not serious outcomes:

No effect (no symptoms due to exposure)

Minor effect (some minimally troublesome symptoms)

Not followed, judged as nontoxic exposure (clinical effects not expected)
Not followed, minimal clinical effects possible (no more than minor effect possible)

Serious outcomes:

Moderate effect (more pronounced, prolonged symptoms) Major effect (symptoms that are life-threatening or cause significant disability)

Death

Unable to follow, judged as a potentially toxic exposure

When the medical outcomes of cases were judged as unrelated to the valsartan ingestion, the cases were excluded from analysis of medical outcome severity.

The serious medical outcome rate (proportion of all cases with a serious medical outcome) was calculated for selected variables. Variables were chosen based on those included in the triage guidelines developed by the AAPCC for other cardiovascular drugs $[10,11]$. Maximum dose was evaluated in two ways: (1) $\leq 320 \mathrm{mg}$ or $>320 \mathrm{mg}$, (2) $\leq 4$ tablets or $>4$ tablets. The $320 \mathrm{mg}$ threshold was chosen because the recommended total daily dose in adults is $320 \mathrm{mg}$ [5]. The four-tablet threshold was chosen because this analysis found that $80 \mathrm{mg}$ tablets are the most commonly reported ingested formulation. Thus, four $80 \mathrm{mg}$ tablets would equal a $320 \mathrm{mg}$ dose. Using Computer Programs for Epidemiologic Analyses (PEPI, http://sagebrushpress.com/ pepibook.html) the differences in serious outcome rates between the subgroups were evaluated for statistical significance by calculating the rate ratio and 95\% confidence interval (CI) by Poisson probability. The rate ratios were considered statistically significant if the 95\% CI excluded 1.00. P-values were not calculated.

Using the triage guideline algorithm tables drafted by the AAPCC for ingestion of other cardiovascular drugs as a model, the results of the above analyses were then utilized to propose a triage guideline algorithm table for the management of adult ingestions of valsartan $[10,11]$. Determining what proportion of cases in this study followed these drafted triage guidelines tested the effectiveness of this triage guideline algorithm.

The Institutional Review Board of the Texas Department of State Health Services considered this research exempt from review.

\section{RESULTS}

From 2000 to 2005, 185 adult ingestions of valsartan were reported to the TPCN. In these cases, valsartan was the only ingested drug. The formulation ingested was known in 93 (50.3\%) cases. Of these cases, the formulation was $40 \mathrm{mg}$ in two (2.2\%) cases, $80 \mathrm{mg}$ in 43 (46.2\%) cases, $160 \mathrm{mg}$ in 42 (45.2\%) cases, and $320 \mathrm{mg}$ in six $(6.5 \%)$ cases. The maximum dose in either milligrams or tablets could not be determined for five (2.7\%) cases. The maximum dose in milligrams was determined for 99 (53.5\%) cases. The mean maximum dose was $346.2 \mathrm{mg}$ (range $80-3,360$ $\mathrm{mg}$ ). The median maximum dose was $300 \mathrm{mg}$. The most frequently reported maximum dose was $160 \mathrm{mg}(\mathrm{n}=35,35.4 \%)$, and the maximum dose was $\leq 320 \mathrm{mg}$ in $81(81.8 \%)$ cases. 
The maximum number of tablets ingested could be determined for 177 (95.7\%) cases. The mean number of tablets was 3.4 (range 1-60). The median number of tablets was 2 tablets. The most frequently reported maximum number of tablets was 2 $(\mathrm{n}=113,63.8 \%)$.

The mean patient age was 55.9 years (range 20-95 years). The patients were male in 54 (29.2\%) cases and female in 131 (70.8\%) cases. The exposure occurred at the patient's own residence in $175(95.6 \%)$ cases. The circumstances of the ingestion were intentional self-harm or malicious intent in 16 (8.6\%) cases (all suspected suicide attempted) and other reasons in 169 (91.4\%) cases. The most common circumstances of ingestion were unintentional therapeutic error, 149 (80.5\%) cases.

The patient was managed on site (at home) in 151 (81.6\%) cases, already at or en route to a health care facility when the poison control center was contacted in 20 (10.8\%) cases, and referred to a health care facility in $14(7.6 \%)$ cases. The final medical outcome was classified as serious in $13(7.0 \%)$ cases, not serious in $164(88.6 \%)$ cases, and considered unrelated to the valsartan in 8 (4.3\%) cases. No deaths were reported.

Table 1 contains the distribution of listed adverse clinical effects by severity of medical outcome. The most frequently reported adverse clinical effects were cardiovascular (particularly hypertension), neurological (particularly dizziness and drowsiness), gastrointestinal, and dermal. A higher proportion of cardiovascular and neurological adverse clinical effects were listed for cases with serious outcomes while a higher proportion of gastrointestinal and dermal adverse clinical effects were listed for cases with not serious outcomes.

Some sort of treatment was recorded for $43.2 \%$ of the cases (Table 2). The most frequently listed treatments were some form of decontamination, particularly dilution (such as drinking water). Other than decontamination, administration of IV fluids was the most commonly reported treatment. A higher proportion of cases with serious outcomes were managed with activated charcoal, cathartic, lavage, and IV fluids while a higher proportion of cases with not serious outcomes were managed with dilution.

Table 3 contains the serious outcome rate for certain variables. The serious outcome rate was significantly higher for cases involving intentional self-harm or malicious intent. Although the serious outcome rate was higher for cases where more than 6 hours had passed between the time of the ingestion and contact with the poison control center, the difference was not statistically significant. The serious outcome rate was significantly greater for higher maximum doses measured in both milligrams and tablets. Serious outcome rates were significantly higher among those patients where health care facilities were involved in their management.

Table 4 shows proposed triage guidelines for adult ingestions of valsartan alone. These guidelines were consistent in the management of the majority of cases. Of those cases where the patient was not already at or en route to a health care facility when the poison control center was contacted and where the proposed triage guidelines were not followed, the majority involved maximum doses
Table 1: Adverse clinical effects listed with adult ingestions of valsartan alone reported to the Texas Poison Center Network, 2000-2005

\begin{tabular}{|c|c|c|c|c|c|c|}
\hline \multirow{2}{*}{$\begin{array}{c}\text { Adverse } \\
\text { Clinical Effect }\end{array}$} & \multicolumn{2}{|c|}{$\begin{array}{l}\text { Not Serious } \\
\text { Outcome }\end{array}$} & \multicolumn{2}{|c|}{$\begin{array}{l}\text { Serious } \\
\text { Outcome }\end{array}$} & \multicolumn{2}{|l|}{ Total } \\
\hline & Number & $\%$ & Number & $\%$ & Number & $\%$ \\
\hline $\begin{array}{l}\text { Any adverse } \\
\text { clinical effect }\end{array}$ & 9 & 5.5 & 8 & 62 & 25 & 14 \\
\hline Cardiovascular & 4 & 2.4 & 5 & 39 & 12 & 6.5 \\
\hline Bradycardia & 0 & 0 & 1 & 7.7 & 1 & 0.5 \\
\hline Hypertension & 4 & 2.4 & 1 & 7.7 & 8 & 4.3 \\
\hline Hypotension & 0 & 0 & 2 & 15 & 2 & 1.1 \\
\hline Tachycardia & 1 & 0.6 & 2 & 15 & 3 & 1.6 \\
\hline Dermal & 2 & 1.2 & 0 & 0 & 2 & 1.1 \\
\hline Edema & 1 & 0.6 & 0 & 0 & 1 & 0.5 \\
\hline Pruritis & 1 & 0.6 & 0 & 0 & 1 & 0.5 \\
\hline Rash & 2 & 1.2 & 0 & 0 & 2 & 1.1 \\
\hline Gastrointestinal & 1 & 0.6 & 0 & 0 & 4 & 2.2 \\
\hline Abdominal pain & 0 & 0 & 0 & 0 & 2 & 1.1 \\
\hline Nausea & 0 & 0 & 0 & 0 & 1 & 0.5 \\
\hline Vomiting & 1 & 0.6 & 0 & 0 & 1 & 0.5 \\
\hline Neurological & 4 & 2.4 & 3 & 23 & 12 & 6.5 \\
\hline Agitation & 0 & 0 & 0 & 0 & 1 & 0.5 \\
\hline Dizziness & 1 & 0.6 & 2 & 15 & 5 & 2.7 \\
\hline Drowsiness & 2 & 1.2 & 1 & 7.7 & 5 & 2.7 \\
\hline Headache & 1 & 0.6 & 1 & 7.7 & 3 & 1.6 \\
\hline Other & 0 & 0 & 1 & 7.7 & 3 & 1.6 \\
\hline Total & 164 & & 13 & & 185 & \\
\hline
\end{tabular}

Cases with multiple adverse clinical effects were included in each adverse clinical effect category.

*Total including 8 cases where the clinical effects were not considered due to valsartan.

above the $320 \mathrm{mg}$ or 4 -tablet limit where the cases were managed on site.

\section{DISCUSSION}

Covering a population of more than 20 million over a recent 6-year period, this investigation provided information on potentially adverse adult ingestions of valsartan reported to poison control centers. In these cases, valsartan was the only ingested drug. Such information is important because clinical studies primarily provided the available literature on such ingestions. Review of the literature failed to identify any such studies using poison control center data. Moreover, although the AAPCC has 
Table 2: Treatments listed with adult ingestions of valsartan alone reported to the Texas Poison Center Network, 2000-2005

\begin{tabular}{|c|c|c|c|c|c|c|}
\hline \multirow[b]{2}{*}{ Treatment } & \multicolumn{2}{|c|}{$\begin{array}{l}\text { Not Serious } \\
\text { Outcome }\end{array}$} & \multicolumn{2}{|c|}{$\begin{array}{l}\text { Serious } \\
\text { Outcome }\end{array}$} & \multicolumn{2}{|c|}{ Total } \\
\hline & Number & $\%$ & Number & $\%$ & Number & $\%$ \\
\hline Any treatment & 71 & 43 & 7 & 54 & 80 & 43 \\
\hline Decontamination & 69 & 42 & 6 & 46 & 77 & 42 \\
\hline Activated charcoal & 7 & 4.3 & 4 & 31 & 13 & 7 \\
\hline Cathartic & 4 & 2.4 & 2 & 15 & 7 & 3.8 \\
\hline $\begin{array}{l}\text { Dilution (e.g., } \\
\text { drinking water) }\end{array}$ & 59 & 36 & 2 & 15 & 62 & 34 \\
\hline Food & 9 & 5.5 & 1 & 7.7 & 10 & 5.4 \\
\hline Ipecac & 1 & 0.6 & 0 & 0 & 1 & 0.5 \\
\hline Lavage & 4 & 2.4 & 1 & 7.7 & 6 & 3.2 \\
\hline Other emetic & 2 & 1.2 & 0 & 0 & 2 & 1.1 \\
\hline Other & 10 & 6.1 & 4 & 31 & 15 & 8.1 \\
\hline Benzodiazepines & 2 & 1.2 & 0 & 0 & 2 & 1.1 \\
\hline IV fluids & 5 & 3 & 2 & 15 & 8 & 4.3 \\
\hline Oxygen & 2 & 1.2 & 0 & 0 & 2 & 1.1 \\
\hline Vasopressors & 1 & 0.6 & 0 & 0 & 1 & 0.5 \\
\hline Other & 6 & 3.7 & 2 & 15 & 8 & 4.3 \\
\hline Total & 164 & & 13 & & 185 & \\
\hline
\end{tabular}

drafted management guidelines for calcium channel blockers and beta blockers, similar guidelines for angiotensin II blockers were not available at the time of this analysis $[10,11]$. US poison control centers currently receive thousands of calls annually concerning such ingestions $[8,9]$.

Several factors should be considered when evaluating the utility of this investigation. It should be noted that bias might be involved in the assignment of the severity of medical outcome. As described in the methods section, medical outcome was assigned by the poison control center staff managing the case and is primarily based on known or expected adverse clinical effects. However, the staff was not blinded to the details of cases and thus may have factored other information (such as the dose or circumstances of the ingestion) into the medical outcome. In prospective studies, cases should not be subject to such a limitation when medical outcome is assigned by individuals blinded to the details.

The maximum dose in milligrams was known for only $54 \%$ of the cases. Studies involving data from poison control centers often exclude cases where the dose is not known. However, it could be argued that excluding such cases might bias the data. Also, emergency care providers might have difficulty determining the exact dose involved in an ingestion. Moreover, the AAPCC triage guidelines include situations for the management of other cardiovascular drugs when the dose is unknown [10,11]. For these reasons, this study included cases when the dose was unknown yet calculated by milligrams and number of tablets.

As an additional limitation, reporting of potentially adverse valsartan ingestions to the TPCN is voluntary. Thus, only a portion of all such ingestions are likely to be reported to the TPCN, and the pattern of exposures included in this study may not represent all such ingestions in the state.

For those cases where the maximum dose in milligrams was known, the mean dose was $346 \mathrm{mg}$, slightly higher than the maximum recommended dose of $320 \mathrm{mg}$ [5]. However, in $82 \%$ of these cases, the ingested dose equaled the maximum recommended daily dose or less. This suggests that in most potentially adverse adult valsartan-only-ingestions reported to poison control centers, the amount ingested will not be greater than the maximum recommended daily dose.

Almost all of the potentially adverse ingestions occurred at the patient's own home and most often involved therapeutic errors such as accidentally taking a double-dose. Thus, health care providers might want to educate their patients carefully to minimize the risk of therapeutic errors. 


\section{Table 3: Severity of medical outcome of adult ingestions of valsartan alone reported to}

the Texas Poison Center Network, 2000-2005

\begin{tabular}{|c|c|c|c|c|c|c|}
\hline Factor & $\begin{array}{l}\text { Serious } \\
\text { Outcome }\end{array}$ & $\begin{array}{l}\text { Not Serious } \\
\text { Outcome }\end{array}$ & Total & $\begin{array}{c}\text { \% } \\
\text { Serious } \\
\text { Outcome }\end{array}$ & $\begin{array}{c}\text { Ratio of \% } \\
\text { Serious } \\
\text { Outcome }\end{array}$ & $95 \% \mathrm{Cl}$ \\
\hline \multicolumn{7}{|l|}{ Circumstance of exposure } \\
\hline Not self-harm or malicious & 5 & 157 & 162 & 3.09 & Reference & \\
\hline Self-harm or malicious & 8 & 7 & 15 & 53.33 & 17.28 & $4.98-67.13$ \\
\hline \multicolumn{7}{|l|}{$\begin{array}{l}\text { Time between ingestion and } \\
\text { PCC contact }\end{array}$} \\
\hline$\leq 6$ hours & 9 & 127 & 136 & 6.62 & Reference & \\
\hline$>6$ hours & 1 & 7 & 8 & 12.5 & 1.89 & $0.04-13.63$ \\
\hline \multicolumn{7}{|c|}{ Maximum reported dose (mg) } \\
\hline$\leq 320$ & 2 & 75 & 77 & 2.6 & Reference & \\
\hline$>320$ & 4 & 13 & 17 & 23.53 & 9.06 & $1.30-100.14$ \\
\hline \multicolumn{7}{|l|}{ \# tablets } \\
\hline$<4$ & 5 & 148 & 153 & 3.27 & Reference & \\
\hline$>4$ & 5 & 12 & 17 & 29.41 & 9 & $2.07-39.11$ \\
\hline \multicolumn{7}{|l|}{ Management site } \\
\hline On site (e.g., home) & 2 & 145 & 147 & 1.36 & Reference & \\
\hline Already at/en route to $\mathrm{HCF}$ & 4 & 14 & 18 & 22.22 & 16.33 & $2.34-180.56$ \\
\hline Referred to HCF by PCC & 7 & 5 & 12 & 58.33 & 42.88 & $8.16-423.00$ \\
\hline \multicolumn{7}{|l|}{$\mathrm{Cl}=$ confidence interval } \\
\hline \multicolumn{7}{|l|}{$P C C=$ poison control center } \\
\hline$H C F=$ health care facility & & & & & & \\
\hline
\end{tabular}

Although one or more adverse clinical effects were reported in $14 \%$ of all cases, no specific adverse clinical effects was listed for more than $4 \%$ of the cases. Observing hypertension as the most frequently reported adverse clinical effect was unexpected because valsartan is used to manage hypertension. The listing of hypertension as an adverse clinical effect may be due to recording errors by the poison control center staff when entering information into the TESS database. Aside from hypertension, the other specific adverse clinical effects reported in this study had generally been found in other studies [1,3-7].

The most commonly listed treatment was some form of decontamination. A higher proportion of recorded cases with serious outcomes were managed with activated charcoal, cathartic, lavage, and IV fluids, treatments most often requiring health care provider involvement. A higher proportion of cases with not serious outcomes were managed with dilution by drinking water, a method that can be performed at home. The reported forms of treatment were consistent with the recommended treatment in the literature $[4,5]$.

This investigation found that certain variables were associated with the severity of medical outcome. Serious medical outcomes were significantly more likely in ingestions greater than $320 \mathrm{mg}$ or 4 tablets. This relationship might be expected since higher doses could accentuate the therapeutic effects of a drug or result in clinical effects not found at lower doses. Serious outcomes were much more likely to occur if the ingestion involved intentional self-harm. Since individuals intending to injure or kill themselves might be expected to take larger quantities of a drug, the observed association between the circumstances of the ingestion and medical outcome is understandable. In fact, in this study, the mean maximum dose was $1,744.0 \mathrm{mg}$ (21.3 tablets) for cases involving self-harm and $271.8 \mathrm{mg}$ (2.1 tablets) for all other cases.

Cases involving a health care facility were much more likely to have serious medical outcomes. Again, this relationship could be due to dose since ingestions involving larger doses might be more likely to be referred to health care facilities. In fact, the mean maximum dose was $250.7 \mathrm{mg}$ (1.9 tablets) for cases managed on site, $1,348.6 \mathrm{mg}$ (10.6 tablets) for cases already at or en route to a health care facility when a poison control center was contacted, and $502.9 \mathrm{mg}$ (12.0 tablets) for cases referred to a health care facility by the poison control center. 


\section{Table 4: Proposed algorithm for triage guidelines for adult ingestions of valsartan alone and}

whether Texas Poison Center Network cases would have followed guidelines

\begin{tabular}{|c|c|c|c|c|c|c|}
\hline \multirow[t]{2}{*}{ Algorithm for triage of adult valsartan exposures } & \multicolumn{3}{|c|}{$\begin{array}{l}\text { Cases not already at/ } \\
\text { en route to HCF: } \\
\text { Guidelines followed? }\end{array}$} & \multicolumn{3}{|c|}{$\begin{array}{l}\text { Cases already at/ } \\
\text { en route to HCF: } \\
\text { Guidelines followed? }\end{array}$} \\
\hline & Yes & No & Total & Yes & No & Total \\
\hline $\begin{array}{l}\text { Is self-harm, suicidal or malicious intent suspected? }[\text { Yes }=\text { to HCF] } \\
{[\mathrm{No}=\text { continue below }]}\end{array}$ & 6 & 0 & 6 & 10 & 0 & 10 \\
\hline $\begin{array}{l}\text { Is patient symptomatic at time of first call? }[\text { Yes = to HCF }] \\
{[\text { No = continue below }]}\end{array}$ & \multicolumn{3}{|c|}{ Unable to evaluate } & \multicolumn{3}{|c|}{ Unable to evaluate } \\
\hline $\begin{array}{l}\text { Has more than } 6 \text { hours passed since the ingestion? }[\text { Yes = on site] } \\
{[\text { No }=\text { continue below }]}\end{array}$ & 7 & 0 & 7 & 0 & 0 & 0 \\
\hline $\begin{array}{l}\text { Does patient have significant underlying cardiovascular disease, } \\
\text { or is he/she taking a beta-blocker or another cardiodepressant } \\
\text { drug? [Yes = to HCF] [No= continue below] }\end{array}$ & \multicolumn{3}{|c|}{ Unable to evaluate } & \multicolumn{3}{|c|}{ Unable to evaluate } \\
\hline $\begin{array}{l}\text { Is the home situation of concern? }[\mathrm{Yes}=\text { to } \mathrm{HCF}] \\
{[\mathrm{No}=\text { continue below }]}\end{array}$ & \multicolumn{3}{|c|}{ Unable to evaluate } & \multicolumn{3}{|c|}{ Unable to evaluate } \\
\hline $\begin{array}{l}\text { Unable to estimate maximum amount ingested? }[\text { Yes = to HCF }] \\
{[\mathrm{No}=\text { continue below }]}\end{array}$ & 1 & 0 & 1 & 0 & 0 & 0 \\
\hline $\begin{array}{l}\text { Maximum total amount possible }>320 \mathrm{mg} \text { or, if dose unknown, } \\
>4 \text { tablets? [Yes = to HCF] }[\mathrm{No}=\text { continue below] }\end{array}$ & 4 & 7 & 11 & 5 & 0 & 5 \\
\hline $\begin{array}{l}\text { Maximum total amount possible } \leq 320 \mathrm{mg} \text { or, if dose unknown, } \\
\leq 4 \text { tablets? [Yes }=\text { on site] }\end{array}$ & 137 & 3 & 140 & 0 & 5 & 5 \\
\hline Total & 155 & 10 & 165 & 15 & 5 & 20 \\
\hline$\%$ of Total & 93.9 & 6.1 & & 75 & 25 & \\
\hline
\end{tabular}

Most of the cases appeared to follow the triage guidelines proposed for the management of adult ingestions of valsartan. This is unsurprising since the cases were originally used to develop the guidelines. It would be interesting to see the proportion of cases of other poison control centers that managed according to these proposed triage guidelines.

Of those cases not managed according to the triage guidelines, most involved doses that would have required the patient to be sent to a health care facility and yet the patient was managed on site (at home). This might suggest that the threshold dose for referring a patient to a health care facility might be too low. Alternately, there might have been additional circumstances that resulted in the patient not being referred to a health care facility.

There are several limitations to these proposed triage guidelines. First, some may disagree with the details of these guidelines, particularly the threshold doses. Additional research would help verify or modify these details.

Second, these guidelines are only useful for adult ingestions of valsartan. Since children have smaller body mass and different metabolisms, the effect of a given valsartan dose likely differs between children and adults. If valsartan is taken with other drugs, the valsartan might interact with the other drugs or the other drugs might be of greater importance when assessing the outcome and management of the ingestion. Thus the guidelines are of limited use for ingestions involving valsartan and other drugs.

Third, these triage guidelines should not be blindly followed when managing adult ingestions of valsartan. One should take the particular circumstances of an ingestion into account when deciding how to manage a particular ingestion.

Finally, the triage guidelines are useful for determining where an ingestion should be managed but not how the ingestion should be managed. The literature suggests decontamination and supportive care for the management of potentially adverse valsartan ingestions. Decontamination at home can be performed by diluting with drinking water. Decontamination at health care facilities can be accomplished via gastric lavage or administration of a cathartic or activated charcoal. Administration of IV fluids can help maintain adequate blood pressure [4,5].

In conclusion, the severity of the medical outcome associated with adult ingestions of valsartan depended on the dose and, possibly as a consequence of dose, the circumstances of the ingestion. The management of patients with severe outcomes was more likely to involve health care facilities. Such information is useful for the creation of triage guidelines.

The authors have no potential financial conflicts of interest to report. 


\section{REFERENCES}

1. Dina R, Jafari M. Angiotensin II-receptor antagonists: an overview. Am J Health Syst Pharm. 2000;57:1231-1241.

2. Israili ZH. Clinical pharmacokinetics of angiotensin II (AT1) receptor blockers in hypertension. J Hum Hypertens. 2000;14 Suppl 1:S73-S86.

3. McInnes GT. Clinical advantage of valsartan. Cardiology. 1999;91 Suppl 1:14-18.

4. Leiken JB, Paloucek FP, editors. Poison and Toxicology Compendium with Symptoms Index. Hudson, Ohio: Lexi-Corp Inc;1998. p. 556.

5. Novartis. Diovan ${ }^{\circledR}$ valsartan tablets. [updated 2006 Apr;cited 2006 Oct 31]. Available from: http://www.pharma.us .novartis.com/product/pi/pdf/diovan.pdf

6. Pfeffer MA, McMurray JJ, Velazquez EJ, Rouleau JL, Kober L, Maggioni AP, Solomon SD, Swedberg K, Van de Werf F, White H, Leimberger JD, Henis M, Edwards S, Zelenkofske S, Sellers MA, Califf RM. Valsartan in Acute Myocardial Infarction Trial Investigators. Valsartan, captopril, or both in myocardial infarction complicated by heart failure, left ventricular dysfunction, or both. N Engl J Med. 2003;349:1893-1906.

7. Cohn JN, Tognoni G; Valsartan Heart Failure Trial Investigators. A randomized trial of the angiotensin-receptor blocker valsartan in chronic heart failure. $N$ Engl J Med.

2001;345:1667-1675.

8. Watson WA, Litovitz TL, Klein-Schwartz W, Rodgers GC, Youniss J, Reid N, Rouse WG, Rembert RS, Borys D. 2003 annual report of the American Association of Poison Control Centers Toxic Exposure Surveillance System. Am J Emerg Med.

2004; $22: 335-404$.

9. Watson WA, Litovitz TL, Rodgers GC, Klein-Schwartz W, Reid N, Youniss J, Flanagan A, Wruk KM. 2004 Annual report of the American Association of Poison Control Centers Toxic Exposure Surveillance System. Am J Emerg Med.

2005;23:589-666.

10. Olson KR, Erdman AR, Woolf AD, Scharman EJ, Christianson G, Caravati EM, Wax PM, Booze LL, Manoguerra AS, Keyes DC, Chyka PA, Troutman WG. Calcium channel blocker ingestion: an evidence-based consensus guideline for out-of-hospital management. Clin Toxicol (Phila).

2005;43:797-822.

11. Wax PM, Erdman AR, Chyka PA, Keyes DC, Caravati EM, Booze L, Christianson G, Woolf A, Olson KR, Manoguerra AS, Scharman EJ, Troutman WG. Beta-blocker ingestion: an evidence-based consensus guideline for out-of-hospital management. Clin Toxicol (Phila).

2005; $43: 131-146$. 